\title{
Chang Chen: a graceful and knowledgeable doctor, both earnest and witty
}

Submitted Apr 17, 2018. Accepted for publication Apr 23, 2018.

doi: $10.21037 /$ jtd.2018.04.158

View this article at: http://dx.doi.org/10.21037/jtd.2018.04.158

\section{Expert's introduction}

Chang Chen, $\mathrm{PhD}$ candidate advisor and professor, is currently the vice president of Tongji University-affiliated Shanghai Pulmonary Hospital and chief physician of Thoracic Surgery of Tongji University-affiliated Shanghai Pulmonary Hospital. He graduated from the Nanjing University Medical School in 1997 . He received state funding in 2002 to study at the Washington University Medical Center in St. Louis, focusing on thoracic surgery and lung transplantation. After returning home, he started his current position in 2004. He became the vice chairperson of the Youth Committee of the Thoracic and Cardiovascular Surgery Branch of Chinese Medical Association in 2016. He was awarded by the Shanghai Leading Talent Program in 2015. He was elected as an International Member of the American Association of Thoracic Surgery (AATS) in 2017. He was named to the "Top 100 Chinese Famous Medical Doctors-Top 10 famous medical doctors of tracheal surgery" in 2013 and 2016.

Professor Chen and his team are deeply involved in the entire course management and precise treatment of thoracic tumor surgery. Their goals are to realize translational medicine and improve therapeutic effects. He leads 17 research projects, including projects from the National Natural Science Foundation of China. He has published 49 SCI papers as the first author or the corresponding author, the main themes of which have been clinical and basic research and clinical application. The highest impact factor of a single article was 24.008 . He also wrote and edited seven monographs.

\section{Humor}

As night fell, the hour hand slowly pointed to the number "8". The operating room of the Tongji University-affiliated Shanghai Pulmonary Hospital (hereafter referred to as the "Pulmonary Hospital") was still brightly lit, and the carts and beds to and from the operating room were still in an

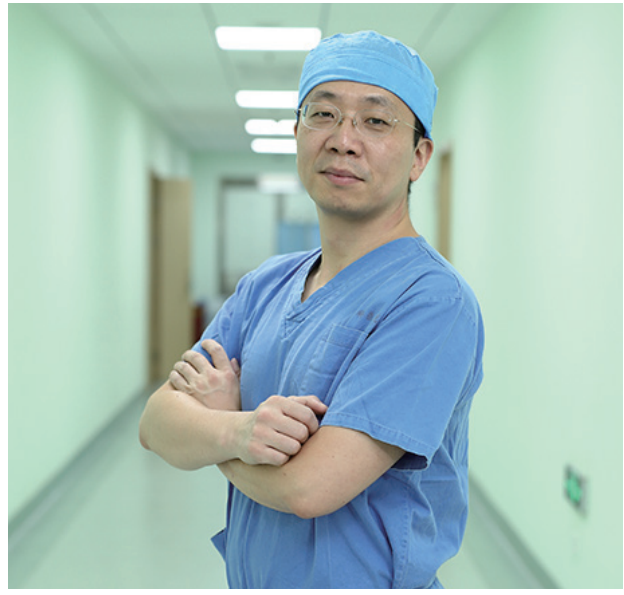

Figure 1 Professor Chen in operating room.

endless stream (Figure 1). In an office in the operating room of the Pulmonary Hospital, Professor Chang Chen, wearing scrubs and holding the background information in hand, slowly answered each interview question from JTD.

JTD asked, "You looks young but you have got a lot of achievements, and you are a promising surgeon, ..."

Professor Chen answered, "Well, thanks. I am no longer young and have not acquired many achievements either."

JTD asked, "Do you have any secret for your rapid success to share?"

Professor Chen answered, "There is no secret-I really think there is none. Now, in retrospect, perhaps my interests were widespread when I was young."

JTD asked, "Apart from your job, do you have any hobbies?"

Professor Chen answered, "I was interested in hairdressing some time ago. Yes, I cut hair for my daughter (laughs) and have been wondering how not to cut it like being nibbled by a $\operatorname{dog} . . . .$. Of course, there are paintings and calligraphy. These hobbies will be continually nurtured after I am retired."

JTD asked, "What was your greatest benefit when 


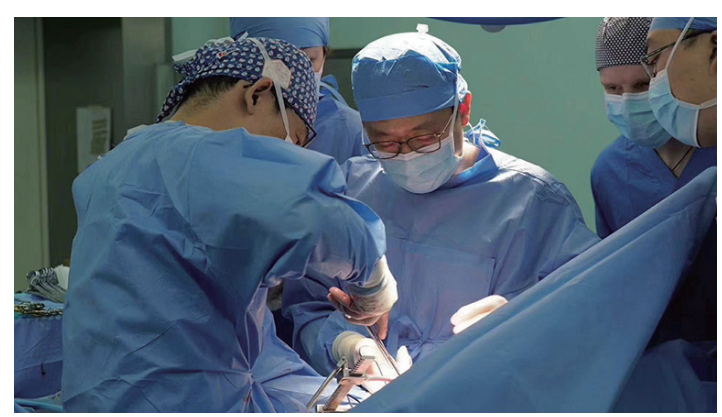

Figure 2 Professor Chen at work.

you were studying at the Washington University Medical Center in the US?"

Professor Chen answered, "I learned the importance of respecting the privacy of patients, mastering the solid basic knowledge of thoracic surgery, and the improvement of my own physical fitness from continuous workouts. When I was in the United States, my abdominal muscles were still 'split', and after I returned home, they became one piece, all joined together."

\section{Earnest}

Professor Chen estimated the time while adjusting the progress of the interview. Just over an hour ago, the interview was nearing completion. He just received a notice from his colleague, "The incision is ready [the surgery is ready for the next step]". After receiving the notification, he quickly pulled himself out of the pleasant interview atmosphere and confirmed with his colleague again, "Is it ready? I will be there [the operating room]." Then, Professor Chen methodically arranged follow-up matters. He finished the dressing and put on a mask. He stepped out of the office slowly but steadily and went to perform the surgery (Figure 2).

At this moment, Professor Chen had inadvertently completely broken the witty and gentle character setting designed by the author during the interview. His rigor and solemnness reminded the author that before becoming a humble and courteous scholar and kind and humorous dean, Chang Chen was a doctor who helps the dying and cures the wounded.

\section{From "accidentally entered a medical career" to "interest cultivation"}

\section{Medical career}

When talking about the old days, Professor Chen stated frankly that he had not originally planned to study medicine. If it had not been for an accident arising from many causes, then he might have already lived abroad. It turned out that the college entrance examination application was filled out by Professor Chen's parents. The first choice was information physics, because it was easier to go abroad, whereas the third choice was the Nanjing University Medical School. But due to the priority admission policy of medical schools, Professor Chen "accidentally entered a medical career".

Although it was a bit of a mistake, Professor Chen admitted that if he had not become a doctor, then he really did not know what kind of job he would be interested in. "I have been taught since I was a kid that an interest can be cultivated, including that in a job. Thus, I have been trying to cultivate my interests in various things."

In view of the educational philosophy of his parents, Professor Chen's cultivation of interests in various things not only included painting and calligraphy but also profoundly influenced his future education path and career path.

\section{Education path}

"As for the secret of success, I think that interest is the best teacher. When I was young, I was interested in many things, and I wanted to try more things, which may have helped me."

When Professor Chen was still a student, the time for study was relatively abundant. He invited six classmates to take turns teaching a class in English, in the hospital. The original intention was good, the plan was feasible, and everyone was interested in it. "After the event was held once, I found that everyone was interested in listening to the talk but not interested in preparing for the talk. After all, it was very difficult for medical students to prepare suitable cases in English and explain them clearly. Eventually, I took on the heavy responsibility all by myself."

Idly poke a stick in the mud, and it grows into a tree to shade you. "Naturally, I could not leave my initiative unfinished. After I insisted on doing it for almost a year, I even had unwittingly talked about all the specialist cases in one US magazine, Postgraduate MED. My general English vocabulary had increased, and my professional English level was also greatly improved."

Having a wide range of interests and daring to try will always lead to results. "Sometimes, my persistence and attempts were the only resort, and sometimes, I did it actively. However, both were helpful."

"Before I went for training in the United States, not only 
did I successfully pass the PETS-5 (National English Test Level 5), I also tried to take all the English certificate exams that were available, and I even memorized the Hongbaoshu (a classical GRE reference book) several times. And just because of this, my English study had improved a lot, and I could be myself."

Now, Professor Chen has been elected as an International Member of the American Association for Thoracic Surgery (AATS). Only ten people in China have received this honor. However, he himself said humbly, "I always thought it was very difficult to be elected as an International Member of AATS, so I just gave it a try and applied for the membership. I was elected only because of my good fortune. I am glad I was born in China and become a member of the thoracic surgery team of the Pulmonary Hospital. Although the English-speaking countries have language advantages, we have more people and case advantages, so the starting line should be the same."

\section{Career path}

It is natural to work as a doctor after studying medicine, but it is a turning point to do administrative work as a doctor. When Professor Chen was concurrently appointed as the vice president of the Shanghai Pulmonary Hospital and just took the position, he was deeply impressed by the challenges in the management work. "I once met a teacher who told me that clinical work and management work use different parts of the brain. The former uses the left hemisphere, while the latter uses the right hemisphere. After I assumed office, I experienced this. The part that has not been developed is suddenly developed. All of a sudden, I encountered many opportunities and challenges."

To this day, Professor Chen still clearly remembers the scene when he first appeared as the vice president. "At that time, I was going to share the future development plan for the hospital's research and teaching. I had been thinking about this issue for a long time."

"To do research and teaching is to find the right resources for the right people and build a platform. This platform can enable people to achieve and grow their abilities, and at the same time, people can create more achievements via this platform. Then, we gradually copied and expanded this platform. My experience in research and teaching management is that not everyone is suitable for the comprehensive development of medical treatment, teaching and research, nor is everyone working with the purpose of comprehensive development of medical treatment, teaching and research. We must find the right role for everyone."
However, what has been troubling Professor Chen is the generation gap between him and the young students. "In many cases, they do not admit that there is a generation gap... I think this challenge is still quite big." He wanted to say something detailed, but hesitated. "There are still a lot of things in real management that I need to learn, and the learning process is more complicated than the clinical work. There is no rule to follow." Despite this, when confronted with the classic multiple-choice question "which one do you like more, management or clinical work?" Prof. Chen used an "old saying" of his own to answer, "It is difficult to say which one I prefer-the interest can be cultivated."

Although Professor Chen shared many challenges regarding his management position, he still remembered to describe the opportunities in it. "To do management work, the basics are to manage the work, but what is more important is to manage people. In fact, the process of managing people is full of opportunities." It is a pleasure to be able to understand young people better and help young people.

\section{From "a young doctor" to "a never younger doctor"}

\section{Cherish the talented}

Although Professor Chen bluntly said that he did not deserve the praise of being young and promising, he was quite generous about sharing his own growth experience, "If we really want to talk about the fast-growing period, then I think it was when I was young and when I really needed nutrients. After I was basically established, the room for growth was also limited. Therefore, on the road to growth, the nutrients unselfishly given by the older generation are very important."

"I have always been very grateful to Professor Jia'an Ding and Professor Gening Jiang." In 2002, Professor Chen received state funding to study at the Washington University Medical Center, and he also received generous support from Professor Ding's research funding for his living costs.

Bearing in mind this kindness and generosity, after serving as the vice president, Professor Chen created many new initiatives in the talent development program, especially for undergraduate students, because he believes that they are in their fast-growing period. Some parts of the talent training program have been completely promoted by Tongji University, which requires every affiliated hospital 
to conduct summer and winter camps, to select college students based on merit, and to perform focused mentoring. Homework that encourages thinking is assigned daily, and case analyses are performed. The goal is to train the clinical practice ability of the students.

“Actually, I don't know whether students like these plans or not. Every time I started the camp, I always shared some stories when I was in medical school with the students. For example, I was assigned to the newborn ward when I was doing the summer break internship. For two weeks in a row, what I did every day was to change diapers for the newborns." Prof. Chen paused a little and then changed the topic, "So, I was very dexterous in changing the diapers for my own kid." During his talking, a slight proud smile appeared on his face.

Today, Professor Chen is no longer young. He regretfully thought that medical students should not simply change diapers for two weeks in a row. Young people should have better educational resources. Therefore, he wants the medical students participating in the camps to know that "at least you will have some more advanced experience than I had."

"Of course, this plan is risky, because these people are not to be hospital staff. We have invested intellectual and financial resources that they may not necessarily pay back to the hospital. However, our original intention when setting up this policy was that even if they may not be able to work for our hospital in the future, we believe that they will cherish this experience. If they are still in the fields of thoracic surgery, respiration or oncology and other related fields, then their experience will play an important role in becoming an expert on this platform and promoting the development of this industry," said Professor Chen.

\section{Cherish the people}

“About five or six years ago, Liu Liu wrote a book called Angel Heart. I spent one night reading the book, and I felt that I had encountered all of the patients whom the main character met.

Among them, there was an old aunt who, after returning home for one or two years after surgery, holding a small note with my identification number on it, told me that she had worshipped Bodhisattva in a temple for me.

Another patient was also like a patient described in Angel Heart. When I was talking to a family member about the medical condition of the patient, I did not expect the patient to eavesdrop at the door. As a result, the patient disappeared the next day. A change in mindset was the main cause.
Working as a doctor for many years, my experience is becoming more and more abundant, and my mood has become more and more peaceful. When I see a patient, I know what kind of needs he or she has for the disease. Some people care little about their health, some people hope to know more about their disease, and some people do not want to be informed of their final diagnosis. Humanistic care should actually go beyond the spiritual civilization that we are talking about now, and it contains many more profound implications.

To me, the more I understand in this area, it means the older I am."

The more the road is traveled, more scenery is seen and more things are cherished.

\section{Cherish bimself}

Professor Chen has been in medical service for more than 20 years. Half of his life has gone, and the dust has settled. Regardless of whether he entered his medical career by accident, he made himself love what he studies through his "education" and "career" paths and has benefitted from them. However, with age, he has more and more regrets, and he occasionally recalls them with emotion and some remorse, but he is more optimistic about his life.

Returning to professional issues, Professor Chen is again serious and humble. This time, Professor Chen talked about perioperative airway management for enhance recovery.

\section{From "experiences" to a "theoretical system"}

\section{Experience}

Enhanced Recovery is a new term, but it is an old problem. "According to my clinical practice experience, many measures that we have been applying bit by bit to accelerate recovery rely on experience." Prof. Chen used senior patients ( 80 years or older) as an example to prove those clinical decisions that reflect the concept of Enhanced Recovery:

First, to reduce postoperative complications, clinicians are accustomed to placing senior patients as the first surgery of the day for those with scheduled surgeries. The reason is that at this time period, the surgeon is full of energy, and the patient is in good physiological condition. Second, the thoracoscopic incision is usually $3 \mathrm{~cm}$. In general, the larger the thoracoscopic incision, the better exposure of the surgical field, and the faster the surgery. If the anesthesia duration is shorter, then the physiological disorders of the 
patients are reduced. Therefore, when treating elderly patients, Professor Chen is more inclined to increase the incision to $5 \mathrm{~cm}$ to shorten the anesthesia duration, which is more conducive to patient recovery. Third, the surgical method is selected based on the degree of tolerance of older patients, such as the range of tumor resection and lymph node dissection.

\section{Theory}

"After the concept of Enhanced Recovery was proposed, it was equivalent to a systematic project proposal, which requires multi-disciplinary collaboration and is thoroughly carried out through the perioperative period of the patient." When the clinician has theoretical support, the clinical decision-making is more versatile and is not determined by the clinician's experience, nor carried out bit by bit. "Many patients with preoperative general anesthesia give up enemas, some high-risk patients undergo anesthesia without intubation, and in some surgeries, we do not provide a preoperative intramuscular injection of atropine to reduce airway secretions..."

It has been a while since the introduction of Enhanced Recovery theory. As experience has developed into a theoretical system, more people are aware of the importance of Enhanced Recovery. "We focus on reducing the interference of surgery on the normal physiological processes of patients. Surgeons increasingly focus on a more precise diagnosis and more precise treatments and start to learn to make a more detailed surgical plan through preoperative multidisciplinary team (MDT) meetings."

At the same time, the nursing team pays more attention to the health education of Enhanced Recovery to improve patient awareness of Enhanced Recovery. This is of great significance for the patient's approval and compliance with the hospital's diagnosis and treatment. Prof. Chen provided an explanation with classical preoperative fasting as an example.

According to previous routine practice, fasting was carried out after $8 \mathrm{pm}$, and water was not allowed after $10 \mathrm{pm}$ the night before the surgery. However, the number of surgeries at the Pulmonary Hospital is very large. At 5 pm in the afternoon on the day of the interview, more than 40 operations were still not completed in the operating room. There are 12 operating rooms at this hospital; therefore, three to four operations were still likely under way in each operating room. By 8 o'clock in the evening, these patients who underwent a consecutive surgery had already fasted for over 24 hours. Prolonged fasting has a serious impact on a patient's internal physiological environment. Excessive gastric acid secretion together with the surgical trauma can easily cause stress ulcers and other issues.

The Pulmonary Hospital normally asks consecutive operation patients to start food fasting from 8 am so that the patients still feel full after 3 or 4 pm in the afternoon. From this perspective, fasting will cause relatively less interference with the physiology of the patients. However, these individualized measures still require cooperation and understanding of the patients. Therefore, it is crucial to improve the patient's awareness of Enhanced Recovery and to provide timely and effective health education by a nursing team.

"After certain things have been written down and become routines, everyone will have a full awareness of them and a high degree of acceptance." Prof. Chen believes that it is the same for Enhanced Recovery.

\section{Interview}

\section{FTD: Is there an evaluation system in place for Enhanced Recovery?}

Professor Chen: At this stage, the evaluation system is very difficult to define, and the absence of a control group is also a problem. Although some projects are under way, these evaluation indicators are difficult to quantify. Therefore, most times, we take some measures from the nursing aspect to observe interference situations.

For example, our Pulmonary Hospital already has a fairly complete set of airway care norms for patients undergoing ordinary lobectomy. The specific nursing measures can be roughly divided into first, encouraging and assisting patients with coughing and expectoration during the perioperative period to expand the lungs; second, after general anesthesia, patients can be encouraged to sit and undergo physical therapy, such as a back massage using a vibration expectoration machine, or inducing cough reflex by gently pressing the suprasternal fossa; and third, nebulized inhalation therapy, which can promote airway function recovery in a patient.

\section{fTD: What are the impacts on patients of taking nursing measures for Enhanced Recovery?}

Professor Chen: It is difficult to quantify the evaluation indicators for Enhanced Recovery, and under the influence 
of medical insurance policies, there is still a long way to go before ambulatory surgery is achieved. However, after the implementation of Enhanced Recovery-related measures, the overall evaluation is still worthy of approval, and these measures are positively correlated with Enhanced Recovery After Surgery with patients. According to the current statistics, the processes of diagnoses and treatment have been improved, and the average duration of hospitalization has been declined.

\section{FTD: What is the role of airway management in the precise diagnosis and treatment plan of thoracic surgery?}

Professor Chen: Airway management is extremely important in the precise treatment of thoracic surgery. Especially in our hospital, which is a pulmonary specialist hospital, there are more types of complex diseases than in a comprehensive hospital. Therefore, from the moment when I entered the pulmonary hospital, the first thing I learned was airway management.

\section{FTD: What is special about airway management in a pulmonary hospital?}

Professor Chen: Pulmonary hospitals have many unique things. When I first started working here, I often encountered patients with bronchial stenosis that was very difficult to handle, and the texture of the scar was very hard. Because patients with airway tuberculosis are relatively young and tolerant, by the time they came for treatment, they could not tolerate asthma. Many times, when I did examinations, I found that the diameter of the entire tracheal lumen was the size of a pinhole (the normal diameter of a trachea is $1.6 \mathrm{~cm}$ for females and $1.8 \mathrm{~cm}$ for males).

Once, there was a patient who was rescued with a tracheotomy at a local hospital because of a trauma. After being transferred to our hospital, the patient had tracheal stenosis complications. The length of the trachea was only 3-4 cm, while the length of the trachea of a normal person is approximately $10 \mathrm{~cm}$. For such a benign lesion, it is impossible to carry out a tracheal resection. Therefore, I performed tracheal truncation and placed a Montgomery T-tube at the stenosis site. This situation is rare.

In addition, the Pulmonary Hospital has a relatively high amount of tracheal tumor cases, and airway management can also provide some extra clinical experience. For example, airway care for large airway tumors is difficult. After the patient undergoes tracheal truncation and resection surgery, the following measures need to be taken within three postoperative days: (I) intravenous injection of large doses of apophlegmatisant; (II) enhanced nebulized inhalation; (III) intravenous administration of small doses of hormones to reduce tracheal anastomotic edema; and (IV) restrictions of head movement to reduce wound tension.

The last kind of airway care is for refractory fistula; even though there are relatively few clinical cases, the treatment strategies and measures are versatile, and relevant academic results have been published.

\section{FTD: Can you describe the treatment for refractory fistula in detail?}

Professor Chen: For example, a complication that is still troublesome in thoracic surgery after airway operation is bronchopleural fistula. Bronchopleural fistula is an abnormal channel formed between the bronchus and pleura. It is one of the most severe complications after pulmonary cancer surgery. It is difficult to treat, and the outcome is poor. According to the occurrence time of a bronchopleural fistula, it can be divided into two types, early-onset and late-onset. Our previous study showed that there was no significant difference in the risk between the two.

Different from the patients with other pulmonary diseases, in terms of care, we pay more attention to the patient's posture. To prevent pleural effusion from entering the lungs and causing infection, we will determine the posture of a patient based on the position of the patient's fistula and prohibit the patient from taking the lateral position on the healthy side. Even if the patient wants to take a supine position, the patient must have their ipsilateral pulmonary lobes raised with a pillow or by other methods. Moreover, these patients must be observed periodically to keep their closed thoracic drainage tube unobstructed and free of air leakage. Moreover, the color and nature of their phlegm should be observed, and whether pleural effusion enters the lung should be determined to timely avoid a pulmonary infection exacerbation.

Just two years ago, we published the study results of the conservative treatment of empyema-complicated postlobectomy bronchopleural fistulas in the Fournal of Thoracic Disease. For empyema-complicated bronchopleural fistulas, treatment is undoubtedly a huge challenge. According to our experience, the first step is to close the fistula to prevent thoracic and pulmonary infections. The second step is drug application. Antibiotics and other drugs are used to treat inflammatory infections in the chest. The specific treatment 
measures can be classified as (I) chest drainage; (II) thoracic lavage; and (III) postural drainage.

\section{FTD: Under the influence of Enhanced Recovery, what are the changes in individualized treatment decisions in clinical practice?}

Professor Chen: Different from previous individualized treatment, we also have many individualized contents during diagnosis. One scientific study that we recently worked on was to refine patient indications. Specifically, we performed individualized case analysis according to different categories, and we hope that we can use a large amount of clinical data to analyze specific patients. Through this study, we can understand what degree of diagnosis individual patients should have under certain conditions, how to develop a treatment strategy, and what impact such treatment strategies may have in the future.

For example, if we are facing a lung cancer patient with ground-glass nodules, we want to know which lymph nodes need treatment and which do not need. Then, we can conduct a clinical study through lymph node dissection and sampling. Through this study, we may be able to reach a conclusion: reducing the clinical interference for some patients can reduce interference with the normal physiological conditions of patients.

Due to the popularization of early screening and the development of modern imaging technology, the discovery rate of small intrapulmonary nodules is high. Traditional guidelines are no longer fully applicable to current patients. Without a theoretical basis, many of our treatment measures can be easily referred to as non-standardized and face many pressures. Therefore, we can develop more precise diagnosis and treatment plans for patients through these clinical studies so that we can achieve faster and better, or at least equivalent, recovery effects with fewer and fewer intervention measures.

\section{FTD: As the vice president of the Pulmonary Hospital, who is mainly in charge of research and teaching, can you talk about a little bit about clinical translational research from the macro perspective?}

Professor Chen: From the perspective of the research assessment index and the goal that is pursued in China's hospitals, it can be roughly divided into two types. One is "bringing in", that is, to invite professors who do basic research to the hospital—some of them are from domestic universities, and some are from overseas. This model is particularly popular at Tongji University, and we have established a translational medicine center for this purpose. The other is the combination of the two, that is, professors working on basic research join clinical teams during their clinical work and even participate in clinical decisionmaking. These professors follow the clinicians during ward checks, discuss each case with them, look for scientific inspiration during the cooperation process, and solve problems raised by clinicians through scientific research.

In recent years, scientific research in our hospital has developed rapidly. I think that one of the secrets is that primarily, all of the clinical research we are doing is based on clinical issues. These clinical studies can in turn guide our clinical practice, and thus, they form a benign cycle and a spiral rise. If patient effectiveness is improved, then more patient trust can be obtained. Thereby, we will have even more opportunities for our development.

FTD: Your paper about the 3D printing of the navigational template for localizing pulmonary nodules, which was published in the Fournal of Thoracic and Cardiovascular Surgery in September of this year, has attracted a lot of attention. Did you use the same model for the clinical study?

Professor Chen: It was somewhat different. At first, our research goal was not to print a navigational template but to print artificial organs. Since 2003, we had already started the organ transplantation experiments. Later, after various attempts, we decided to change our research direction. On that day, when we had a group meeting, we happened to talk about some issues about the application of $3 \mathrm{D}$ printing technology in navigation technology. The localization with a navigational template was initially applied for breast masses. Coincidentally, we were inspired to determine if this technique could be used for a navigational template to localize pulmonary nodules.

However, there are still many differences between localizing breast and pulmonary nodules. We found that there were many tricks, and five students voluntarily formed a technical research group to work on $3 \mathrm{D}$ navigational templates for localization. Since the official establishment of the technical research group, we started the patent design. We discussed how to design such a template in detail.

When this technology was completed, we decided to use it as a medical product in clinical practice. The publication of this article is a result of exploratory research. Thus far, 
we have demonstrated that our navigational templates for localization have the same effectiveness and safety compared with traditional technologies.

\section{FTD: Can you further describe the navigational template $3 D$ printing technology?}

Professor Chen: 3D printing is widely used in orthopedics to print bone materials. Therefore, it is mostly used to print the sternum in thoracic surgery. The sternum is a "real material" that can be placed in the body of a patient, allowing the family members to really see its use. What we print is a "targeting device", a device that can assist doctors to fully achieve automation and precision. It is necessary to explain it clearly to the family members.

This technology can effectively reduce the specialist training of clinicians and shorten the learning curve. More than $90 \%$ of its localization can meet the needs of clinicians. It can also reduce the daily operation steps, relieve the clinical stress burden, and improve its original efficiency by $1 / 4$ to $1 / 3$. At the same time, it can reduce the exposure of patients and doctors to radiation by $1 / 5$ to $1 / 4$.

This technology can also be developed to be more precise in the future and be applied in various disciplines. For example, intraoperative localization is more convenient, biopsies of infected lesions/tumors are more precise, infection/planting does not occur as often, and it can be used to detect pleural effusion volume. Of course, if a very precise localization needs to be achieved, more effort is needed.

\section{Epilogue}

A graceful and knowledgeable doctor, once works on it, then becomes an expert on it.

A graceful and knowledgeable doctor, once feels regretful, then makes it up.

A graceful and knowledgeable doctor, humorous and humble, dedicated and solemn, earnest and witty.

\section{Acknowledgements}

Special thanks to Professor Chang Chen and Head Nurse Bei Chen of Shanghai Pulmonary Hospital Affiliated to Tongji University and Ms. Lili Liao from AME Publishing Company for their strong support.

\section{Footnote}

Conflicts of Interest: The author has no conflicts of interest to declare.

(Science Editor: Reeyan Jiang, JTD, jtd@amepc.org)
Cite this article as: Jiang R. Chang Chen: a graceful and knowledgeable doctor, both earnest and witty. J Thorac Dis 2018;10(Suppl 11):S1251-S1258. doi: 10.21037/jtd.2018.04.158 